\title{
Tornando-se japonês: literatura de viagem em busca de identidade nacional
}

JEFFREY LESSER*

Resumo: A partir da literatura de viagem sobre o Japão, o autor procura mostrar como do final do século XIX até depois da Segunda Guerra Mundial esse país foi encarado como modelo a ser seguido na construção da nacionalidade brasileira.

Abstract: The author shows how travel literature since the end of the 19th century until post World War II years presentes Japan as a model for the construction of Brazilian nationality.

Palavras-chave: Imigração Japonesa. Quistos étnicos. Segunda Guerra Mundial.

Key words: Japanese immigration. Ethnic systs. World War II.

Em termos de violência formal, a Segunda Guerra Mundial teve pouco impacto sobre a maioria dos brasileiros. Para estrangeiros, especialmente dos países inimigos, porém, a entrada do Brasil na "Grande Guerra" criou uma situação muito tensa. ${ }^{1}$ Para os 200.000 membros da comunidade japonesa no Brasil e para o mais de meio milhão de brasileiros de descendência japonesa, a entrada do Brasil na guerra se refletiu num período de terror, de expulsão de suas casas e propriedades, de acusações falsas e de

Professor no Connecticut College, New London, EUA.

Uma versão deste texto foi apresentada no painel "Fronteiras Brasileiras da Segunda Guerra Mundial", no XX Simpósio da ANPUH, 1999, Florianópolis, Brasil. Gostaria de agradecer aos professores Roney Cytrynowicz e Murilo Marcondes de Moura por seus valiosos comentários. A revisão da tradução, bem como o resumo, o abstract e as palavras-chave são de René E. Gertz. 
manifestações antijaponesas entre a população, encorajadas pelo governo brasileiro.

Mesmo que as atitudes antijaponesas que explodiram depois de 1942 possam ser facilmente derivadas de um latente antiniponismo existente no Brasil antes da guerra, vale a pena lembrar que também houve um grande número de poderosos membros da elite brasileira que havia apoiado de forma explícita a entrada de imigrantes japoneses, um projeto encarado por muitos como bem sucedido em termos econômicos e sociais.

Para muitos membros da elite, os japoneses e seus descendentes eram vistos como salvadores, como trabalhadores dedicados, dóceis e "brancos", que ajudariam a transformar o Brasil num Japão sul-americano: produtivo, forte, autoritário e homogêneo. Essa visão positiva do Japão estava tão arraigada na mentalidade da elite, que mesmo o novo status do Japão inimigo, depois de 1941, pouca mudança trouxe para essa atitude implícita.

Uma das mais fascinantes maneiras de examinar como o Japão era refletido no Brasil pode ser feita a partir dos livros de viagem escritos por brasileiros que visitaram a Ásia nos anos 1920 , 1930 e 1940. Abordo esse tema com mais vagar no meu livro Negociando a identidade nacional, ${ }^{2}$ mas aqui gostaria de centrar meu foco nos brasileiros que escreveram durante a época da guerra. Mesmo que nesses livros o discurso sobre o Japão, na superfície, tenha mudado muito depois de 1942, quando o Brasil virou "aliado" e o Japão "inimigo", manteve-se o contorno mais profundo, enraizado na mente da elite brasileira, e o Japão continuou sendo o modelo de sucesso a ser seguido, sendo amigo ou inimigo.

No Brasil há um ditado que se encontra com frequiência e que diz que "se cavares um buraco suficientemente profundo, acabarás no Japão". Quando a imigração japonesa para o Brasil atingiu seu auge, um quarto de século depois de iniciada, a relação popular entre os dois países encontrou a sua expressão em uma série de livros de viagem escritos pelas elites brasileiras. Cada um desses livros procurou explicar, de forma superficial, a cultura japonesa para a população brasileira, e também explicar como o fluxo da imigração japonesa iria refletir-se no Brasil. Mas esses temas constituíam somente a fachada de uma consideração mais complexa de

Lesser Jeffrey. Negotiating national identity: immigrants, minorities and the struggle for etnicity in Brazil. Durham/London: Duke University Press, 1999. 
identidade nacional, na qual o futuro do Brasil estava sendo imaginado a partir do Japão.

A Ásia representava a base da experiência não-européia da pós-escravidão no Brasil, e os viajantes para a região eram observadores descompromissados. Muitos dos seus pensamentos pessoais tornaram-se públicos através da literatura e de discursos. Do final do século XIX até aproximadamente 1950, diários de viagem sobre o "Oriente" foram editados pelas maiores editoras comerciais do Brasil. Os viajantes podiam ser clérigos ou militares, psicólogos ou artistas, mas todos tinham em mente um mesmo objetivo: um Brasil imaginado através de uma lente que era "a condição do outro". Pessoas tornavam-se objetos e objetos foram "subjetivados", em uma tentativa de compreender o futuro interno explorando desenvolvimentos sociais e econômicos no exterior. Viajantes brasileiros construíram um Brasil a milhares de quilômetros do lugar em que ele se encontrava fisicamente. Descrições desse "outro lugar" foram sempre esperanças para o "aqui".

Foi a Restauração Meiji, com suas modificações radicais no sistema político-econômico, que produziu um modelo para o crescimento interno e o poder internacional. O Japão pareceu ganhar, da noite para o dia, riqueza, poder e modernidade, e o crescente número de trens, bondes, soldados e fábricas encaixouse de forma perfeita nas aspirações brasileiras. Intelectuais se

\footnotetext{
A maioria das análises acadêmicas da literatura de viagem concentra-se em visões de "primeiro mundo" sobre regiões coloniais. SAID, Edward. Orientalism. New York: Random House, 1978; PRATT, Mary Louise. Imperial Eyes: Travel writing and transculturation. London/New York: Routledge, 1992; PRASSAD, Ram Chandra. Early English travellers in India: a study in the travel literature of the Elizabethan and Jacobean Periods with particular reference to India. 2. ed. Delhi: Motilal Banarsidass, 1980; SPURR, David. The rhetoric of empire: colonial discourse in journalism, travel writing, and imperial administration. Durham: Duke University Press, 1993; SÜSSEKIND, Flora. O Brasil não é longe daqui: o narrador, a viagem. São Paulo: Companhia das Letras, 1990; GREENBLATT, Stephen. Marvelous possessions: the wonder of the new world. Chicago: University of Chicago Press, 1991; YOKOYAMA, Toshio. Japan in the Victorian Mind: $a$ study of stereotyped images of a Nation, 1850-80. London: Macmillan, 1987; BEHDAD, Ali. Belated travelers: orientalism in the Age of Colonial dissolution. Durham: Duke University Press, 1994; MULVEY, Christopher. Anglo-American Landscapes: a study of nineteenth-century Anglo-American travel literature. Cambridge: Cambridge University Press, 1983; ANDERSON, Patrick. Over the Alps: reflections of travel and travel writing, with special reference to the Grand Tours of Boswell, Beckford and Byron. London: Rupert Hart-David, 1969; THOMAS, Nicholas. Colonialism's culture: anthropology, travel and government. Princeton: Princeton University Press, 1994; PAGDEN, Anthony. The Effacement of Difference: Colonialism and the Origins of Nationalism in Diderot and Herder. In: PRAKASH, Gyan (ed.). After colonialism: imperial histories and postcolonial displacements. Princeton: Princeton University Press, 1995, p. 129-152.
} 
surpreenderam com os avanços da ciência e da medicina dos japonesas, e os políticos se sentiram atraídos pela expansão militar e pelo Estado autoritário. Todos se questionavam como a população de japoneses e descendentes no Brasil, que na primeira década do século $X X$ atingia muitos milhares, iria afetar a identidade nacional.

Narrativas de viagens brasileiras sobre o Japão distinguem-se dos livros e artigos escritos por viajantes "ocidentais" sobre o "Oriente". Confiantes imperialistas europeus e norte-americanos retrataram a Ásia como um lugar a ser ocupado, possuído, e talvez redimido. No entanto, nas representações de viajantes brasileiros havia uma tendência de tomar o Japão como modelo a ser seguido, e não para ser possuído. Todo viajante esperava encontrar no Japão artefatos culturais e inovações tecnológicas que iriam melhorar o clima social do Brasil e seu lugar na ordem internacional. Mesmo assim, os viajantes para o Japão estavam, em seu conjunto, convencidos de que suas raízes e ligações com a Europa os faziam superiores aos asiáticos. Eles se sentiam, portanto, como membros dos dois mundos, o "primeiro" e o "terceiro", e sua aspiração de imitar o Japão nas esferas econômica e militar se sobrepunha à repulsa à sua tradição não-cristã. Se uma confiança absoluta caracteriza a maior parte das imagens não-brasileiras da Ásia, os textos brasileiros estão marcados pela falta de exatidão. É simplesmente impossível imaginar Lafcadio Hearn (dos Estados Unidos) ou Sir Rutherford Alcock (da Grã-Bretanha) concordarem com o embaixador brasileiro Manuel de Oliveira Lima de que os japoneses "[...] são tolerados, na prática, pelas vantagens materiais".

$\mathrm{Na}$ verdade, os viajantes brasileiros tinham um conhecimento sem profundidade. Suas visitas eram relativamente curtas e poucos falavam a língua local. Todos tinham lido trabalhos de "japonologistas" portugueses. O intercâmbio freqüente de introduções e prefácios entre eles deu origem a um discurso pouco diversificado sobre o Japão. A maior parte dos livros foi publicada pelo governo ou por editoras de prestígio, e muitos títulos chegaram a segundas e terceiras edições, ao mesmo tempo em que atores importantes do processo de decisão olhavam para os viajantes como mediadores entre a vivência e a ação. Tão logo retornavam,

ALCOCK, Rutherford. The capital of the Tycoon: a narrative of a three years' residence in Japan. New York: Harper \& Brothers, 1863; HEARN, Lafcadio. Glimpses of unfamiliar Japan. Boston: Houghton, Mifflin \& Company, 1894; Lima, Manuel de Oliveira. No Japão: impressões da terra e da gente. 2. ed. Rio de Janeiro: Laemmert, 1905, p. 326. Yokoyama, Japan in the Victorian Mind, p. 67-72. 
os visitantes do Japão eram procurados para conferências e para entrevistas a importantes jornais. Bajulavam a mídia e as classes média e alta, contribuindo, dessa forma, para a formação de imagens entre os habitantes das cidades, que tinham pouco contato com os imigrantes japoneses e seus descendentes que viviam nas áreas rurais no Brasil.

O que chama a atenção em relação aos relatos de viagem é como, ao longo de cinco décadas, os enfoques se mantiveram similares. Antigos capítulos históricos retratam um Japão prémoderno, selvagem e precário, que, de repente, se transforma num poderoso Estado moderno através de Meiji. Estatísticas sobre produção e fotografias de indústrias pesadas e edifícios de estilo ocidental sugerem que o inevitável subproduto do fortalecimento econômico era a modernidade cultural. O Japão a que se aspirava era um Japão ocidentalizado, cheio de bondes e arranha-céus feitos de materiais duradouros. Capítulos sobre hotéis modernos e suas elegantes salas de chá inglesas - sendo o mais conhecido o Hotel Imperial desenhado por Frank Lloyd Wright e inaugurado em Tóquio em 1922 como residência oficial para dignitários estrangeiros - eram quase obrigatórios. ${ }^{5}$ O Japão recebeu um verniz moderno, e assim: ocidental, servindo, dessa forma, como mediador da aspiração brasileira para atingir esse status. A esperança do futuro do Brasil estava no Japão.

O Japão moderno que os brasileiros veneravam, porém, também tinha um lado negativo. A preservação da cultura tradicional, diferente de objetos tradicionais, incomodava os viajantes. Se estátuas gigantes de Buda e castelos da era Shogun eram impressionantes, pessoas "não-ocidentais" eram problemáticas. É claro, essa forma de pensar é típica do discurso colonialista europeu e norteamericano, no qual homens e mulheres asiáticos são feminilizados, para que possam ser dominados e descartados. Os brasileiros não seguiram esse modelo. Em vez disso, os homens eram retratados sob uma luz positiva, dando a impressão de uma população moderna, trabalhadora, inteligente, e rumando para o futuro. Mas as mulheres representavam, ao mesmo tempo, o passado, - do qual o Brasil queria fugir - e as "secretas" fantasias masculinas.

Esse dualismo determinado pelo gênero expressava a contradição entre o Japão odiado e o Japão desejado. Ao contrastar o homem moderno e a mulher japonesa dócil, doméstica, e comple-

JAMES, Cary. The Imperial Hotel: Frank Lloyd Wright and the Architecture of Unity. Rutland/Tokyo: Charles E. Tuttle, 1968; LEVINE, Neil. The Architecture of Frank Lloyd Wright. Princeton: Princeton University Press, 1996, p. 114-124. 
tamente não-moderna, o brasileiro afirmava sua superioridade de "primeiro mundo" (isto é: européia), enquanto expressava sua inferioridade de "terceiro mundo" (isto é: brasileira). Mesmo que os estereótipos culturais ocidentais imaginassem um Japão de mulheres exóticas e misteriosas, a eficiência do espírito de modernidade não podia ser ignorada. Contrastando o homem moderno e a mulher tradicional, podia explorar a imigração japonesa tanto sob o prisma da esperança quanto da cautela. Ao sugerir que alguns japoneses eram melhores, atribuía-se um novo papel ao Estado (ao qual estavam vinculados todos os viajantes), tanto como promotor quanto como protetor da pátria brasileira.

A noção de gênero dual não se encontra nos escritos brasileiros sobre o Oriente Médio ou outras partes da Ásia, principalmente a Índia e a China. Nessas narrativas, os viajantes masculinos levam civilização a "culturas atrasadas", povoadas por homens fracos e intoxicados, e mulheres envolvidas em vidas de promiscuidade sexual e serviço doméstico. ${ }^{6}$

Os aspectos singulares do gênero dual do Japão não devem sugerir que os diários de viagem não fossem fortemente orientados para o sexo. $\mathrm{Na}$ realidade, à primeira vista, a natureza luxuriosa desses diários é surpreendente, dado que os seus autores eram membros de uma elite treinada a não ofender sensibilidades delicadas. $\mathrm{O}$ afastamento de casa deu uma certa liberdade à imaginação, e, para os brasileiros que procuravam um futuro no Japão, o sexo fornecia o clima. Em 1933, Gilberto Freyre escreveu que "o meio no qual a vida brasileira começou era o de uma intoxicação sexual", e no Japão os brasileiros procuravam a reencarnação. Esses autores, que em casa eram ao mesmo tempo sexualmente reprimidos e sexualmente ativos (com mulheres de "raças" e classes diferentes), ficavam intrigados, excitados e assustados com a sexualidade aberta que viam no Japão. O custo de retratar uma cultura japonesa singular e unitária teve um preço muito alto paro os brasileiros, que tinham tanta certeza do futuro quanto receio do passado.

Uma construção similar pode ser encontrada nos comenários de Henrique C. R. Lisboa sobre o Japão (Os chins do Tetartos. Rio de Janeiro: Typographia da Empresa Democrática Editora, 1894, p. 149). Um artigo provocante sobre gênero e literatura de viagem encontra-se em Montrose, Louis. The World of Gender in the Discourse of Discovery. In: Greenblatt, Stephen. New World Encounters. Berkeley: University of California, 1993, p. 177-217.

Freyre, Gilberto, The Masters and the Slaves: a study in the development of Brazilian civilization. 2. ed. Berkeley: University of California Press, 1986, p. 85. 
Enquanto os livros de viagem sobre o Japão escritos antes de 1937 estavam cheios de figuras de linguagem sugerindo o desejo de imitação, a instituição do Estado Novo deu origem a um certo número de publicações inspiradas pelo discurso oficial do governo. No começo do Estado Novo, Vargas estava impressionado com o Japão por duas razões: era um mercado importante e tinha um governo autoritário similar ao brasileiro. Em dois anos, a Companhia Editora Nacional publicou dois livros sobre o Japão e a Editora Record mais um. Os três mostravam o Japão num sentido positivo, centrados no Japão moderno. Todos apresentavam o fascismo como um sistema político importante para o Brasil e sublinhavam isso com fotografias sobre educação física em massa e sobre a grande produção industrial. ${ }^{8}$

Em 1941, porém, as coisas começaram a mudar. O Brasil se inclinou para os aliados e rompeu suas relações com o Japão, e, como mostrou Roney Cytrynowicz, o Estado Novo utilizou idéias de "inimigos" para criar uma frente interna que deixou os grupos associados ao Eixo numa posição precária. ${ }^{9}$ De repente, as imagens positivas sobre Japão e seu povo (incluindo imigrantes e seus descendentes no Brasil) mudou. Em vez de uma nação a ser admirada, o Japão agora era um inimigo, e a literatura de viagem passou a refletir essa mudança. Os três livros sobre o Japão escritos por José de Lima Figueirêdo evidenciam esse aspecto. Figueirêdo era militar (em 1951, depois de promovido a general no segundo governo Vargas, foi eleito deputado federal por São Paulo), enviado para observar os conflitos na Ásia depois do estabelecimento do Estado de Mandchucuo pelos japoneses em 1932. Ficou no Japão até 1937 como adido militar, e depois de sua volta ao Brasil ascendeu dentro do Estado Novo, escrevendo, com freqüência, artigos na revista mensal Cultura Política. As publicações de Figueirêdo foram muito respeitadas e o seu livro No Japão foi assim (1941), que denotava uma grande admiração por esse país, ganhou o prêmio

BAHIANA, Henrique Paulo. O Japão que eu vi. São Paulo: Nacional, 1937; MENDES, Armando. O Japão que avança: aspectos econômicos, estudos e impressões de viagem ao Japão. São Paulo: Record, 1937; DANTAS, Garibaldi. Extremo Oriente. São Paulo: Nacional, 1938; SOUZA, Claudio. Impressões do Japão. Rio de Janeiro: Instituto Brasileiro de Cultura Japonesa, 1940. Em 1928 Souza publicara uma obra em 2 volumes sobre sua viagem ao Oriente Médio (De Paris ao Oriente. Rio de Janeiro: Graphica Sauer, 1928).

CYTRYNOWICZ, Roney. Guerra sem guerra: a mobilização e a constituição do "front interno" em São Paulo durante a Segunda Guerra Mundial (1939-1945). São Paulo: USP, 1998 (tese de doutorado), p. 243-280. 
de melhor livro num concurso organizado pelo Instituto Brasileiro de Cultura Japonesa. ${ }^{10}$

Quando o Brasil declarou guerra ao Japão, Figueirêdo fez o mesmo. O Japão por dentro (1944) constitui propaganda pura, cheio de "samurais modernos...que choram porque uma flor bonita se desfolhou [e] riem ao verem um chinês ser rachado". A cultura admirável explorada no livro anterior sumiu: agora o Japão virou "uma imensa caserna, [onde] os homens nascem para ser soldados". ${ }^{11}$ Imagens buscadas na propaganda norte-americana foram importantes na nova visão de Figueirêdo. "O espírito militar é adquirido no berço pelo nipão", escreveu, criando uma nova palavra derrogatória - nipão - do inglês "nip". ${ }^{12}$ Um capítulo tinha um título em inglês, "Spy Mania", e foi rasgado e traduzido para português na cópia que utilizei na Biblioteca Mário de Andrade.

O que chama a atenção em O Japão por dentro é como a nova interpretação do Japão não modificou a busca da identidade nacional brasileira que caracteriza a literatura de viagem desde o começo do século. Para Figueirêdo, no Japão "há uma 'melange' étnica de ainus (brancos), malaios (negróides) e chineses, mandchús e mongóis (amarelos)..., entretanto, não interessa, porque... todos os japoneses são perfeitamente iguais". Assim, na visão do autor, a diferença de raças existente no Brasil também existiu no Japão, com uma única diferença: o Japão foi bem sucedido em fazer desaparecer o "colorido" do rosto da raça nacional.

Figueirêdo evidentemente enxergou o Japão como modelo para o Brasil, mas, mesmo assim, classificou-o como inimigo, culpando com frequiência as mulheres. Gueixas foram transformadas de desejáveis objetos sexuais em guardadoras de segredos nacionais. As mulheres "vêm ao mundo para serem mães de soldados..., sublime sacrifício - dedicar todos os seus sonhos de virgem a um homem que não conhecem", usando os seus corpos para "reconstruir a economia do país do sol nascente". ${ }^{13}$ Essa noção teve impacto direto no Brasil, agora cheio de "verdadeiros quistos raciais". A única esperança era acabar com a imigração japonesa, que ia forçar as mulheres japonesas a se casarem com homens brasileiros. ${ }^{14}$

10 FIGUEIRÊDO, José de Lima. No Japão foi assim. Rio de Janeiro: Editora Século XX, 1941. A visão de Figueirêdo sobre o Brasil pode ser vista em A Conquista do Brasil pelos Brasileiros (Rio de Janeiro: Conselho Nacional de Geografia, 1943).

1 FIGUEIRÊDO, José de Lima. O Japão por dentro. São Paulo: Nacional, 1944, p. 7.

12 Ibid.

13 Ibid., p. 7-8; 29; 33.

14 Ibid., p. 75-77. 
Figueirêdo apresentou ao público brasileiro um Japão perigoso, mas seu contemporâneo Mário Botelho de Miranda penetrou profundamente na cultura local virando japonês. Botelho estudou a língua japonesa (além de francês, espanhol e inglês) e foi um dos fundadores do Grêmio Cultural Brasileiro-Nipônico em São Paulo. Como suas habilidades lingüísticas e a direção da Liga Nacional de Jiujitsu o ligavam à comunidade nikkei, pôde declarar: "No fim, conheci só um Japão no Brasil". Nessa condição, o jovem Botelho aceitou com muita emoção a oportunidade ir ao Japão com um grupos de alunos da USP em 1940. Depois de dois meses, todos os alunos voltaram ao Brasil, menos um que queria descobrir o Japão, "sempre escondido dos olhos dos turistas e visitantes oficiais". Por três anos Botelho foi funcionário do governo brasileiro no Japão, adquirindo fluência no japonês e vencendo a competição nacional de oratória para estrangeiros em 1941. Quando o Brasil rompeu relações com o Japão em 1942, foi repatriado e durante as investigações sobre o Shindo Remmei, depois da guerra, foi nomeado tradutor oficial da polícia.

Na capa do livro de Botelho, cujo titulo é Um brasileiro no Japão em guerra, há uma espada com os ideogramas "Japão na Guerra", a qual atravessa uma cena serena de duas gueixas andando em frente do Monte Fuji. A capa foi criada claramente para ser profundamente provocativa e para sugerir três coisas: a experiência especial de Botelho, a sexualidade das mulheres no país, e a agressividade dos homens. O prefácio do livro foi escrito por Nelson Tabajara de Oliveira, um fiel seguidor de Vargas, que também escreveu vários livros sobre o Japão. ${ }^{15}$ Tabajara conheceu Botelho em Tóquio e ficou impressionado com a pessoa deste, mas cauteloso em relação à sua visão. Na verdade, no contexto da Segunda Guerra, Tabajara repudiou seus próprios "erros" por escrever positivamente sobre o Japão, e preveniu os leitores que Botelho se "identifica rigorosamente" com o país. Mais uma vez mostrando a influência da propaganda norte-americana sobre os livros escritos durante a guerra, Tabajara terminou seu prefácio com três palavrinhas em inglês: REMEMBER PEARL HARBOR. ${ }^{16}$

${ }^{15}$ OLIVEIRA, Nelson Tabajara de. Shanghai: Reportagens do Oriente. São Paulo: Nacional, 1934; OLIVEIRA, Nelson Tabajara de. O Roteiro do Oriente. 2. ed. São Paulo: Nacional, 1935; OLIVEIRA, Nelson Tabajara de. Japão: reportagens do Oriente. São Paulo: Nacional, 1934.

${ }^{6}$ OLIVEIRA, Nelson Tabajara de Oliveira. Considerações de Nelson Tabajara de Oliveira. In: MIRANDA, Mário Botelho de. Um brasileiro no Japão em guerra. São Paulo: Nacional, 1944, p. 11-13. 
$\mathrm{O}$ discurso de Tabajara sobre gueixas e samurais perigosos foi rejeitado por Botelho. ${ }^{17}$ De fato, Botelho era um observador bem diferente do que seus compatriotas - para exemplificar: durante a viagem ao Japão, no navio Brasil-Maru, conversou tanto com imigrantes japoneses residentes na América Latina quanto com refugiados judeus. No Japão, suas percepções também foram curiosas. Reconheceu, por exemplo, que a maioria das mulheres no Japão trabalhava fora de casa, ao mesmo tempo que reconhecia que havia espaços sociais bem diferentes para homens e mulheres. Uma análise dos meios do transporte desembocou numa discussão sobre o trabalho de mulheres nesse setor. ${ }^{18}$ Se as mulheres parecem ser "escravas", escreveu, os autores ocidentais não entenderam o que estava acontecendo. Inclusive um capítulo sobre prostituição levantou uma questão metodológica que até hoje é controvertida: se existe uma moralidade absoluta para todas as culturas.

Talvez a história mais importante em Um Brasileiro no Japão em Guerra fosse uma fofoca que Botelho disse ter ouvido num parque público. Ao sugerir que a historinha era acessível apenas a pessoas que falavam japonês (como ele, Botelho), lança uma rápida luz sobre um mundo secreto, o mesmo mundo que muitos brasileiros imaginavam existir dentro da comunidade japonesa no Brasil. A história, por um lado, representava o Japão odiado pelos brasileiros, mas, no fim, virou um ritual de nacionalismo a que os brasileiros deveriam responder:

"Um candidato a deputado, para conseguir alguns milhares de ienes urgentes para as despesas e depósitos necessários à sua campanha eleitoral, 'penhorou' sua esposa no Yoshiwara. Seus correligionários, sabedores do fato, trabalharam com mais denodo para sua vitória no pleito. Sendo eleito, fizeram, os seus amigos, uma arrecadação monetária entre eles - e pagaram pela rescisão do 'contrato', levantando o 'penhor'. Foram tidos pelos jornais e pela voz popular como heróis que se sacrificaram pelo país [...]."19

O Brasil estava em guerra com o Japão, mas os japoneses permaneceram como o modelo de como construir o país do futuro.

17 Miranda, Um Brasileiro no Japão, p. 15.

${ }_{18}$ Ibid., p. 74; 112. O único outro autor que citou esse fato foi Augusta Peick Moreira.

19 Ibid., p. 135. 